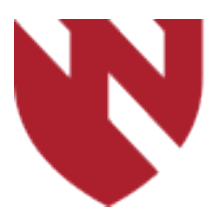

December 2020

\title{
Customized Blister Packaging for Patients Living with HIV: Assessment of Patient Attitudes and Satisfaction
}

\author{
Holly Groteluschen \\ University of Nebraska Medical Center \\ Harlan Sayles \\ University of Nebraska Medical Center \\ Rebecca Osborn \\ Yale School of Medicine \\ Joshua P. Havens \\ University of Nebraska Medical Center \\ Sara Bares \\ University of Nebraska Medical Center
}

See next page for additional authors

Tell us how you used this information in this short survey.

Follow this and additional works at: https://digitalcommons.unmc.edu/gmerj

Part of the Infectious Disease Commons, Other Pharmacy and Pharmaceutical Sciences Commons, and the Virus Diseases Commons

\section{Recommended Citation}

Groteluschen $\mathrm{H}$, Sayles $\mathrm{H}$, Osborn R et al. Customized blister packaging for patients living with HIV: assessment of patient attitudes and satisfaction. Graduate Medical Research Journal (2020).

This Original Report is brought to you for free and open access by DigitalCommons@UNMC. It has been accepted for inclusion in Graduate Medical Education Research Journal by an authorized editor of DigitalCommons@UNMC. For more information, please contact digitalcommons@unmc.edu. 


\title{
Customized Blister Packaging for Patients Living with HIV: Assessment of Patient Attitudes and Satisfaction
}

\author{
Abstract \\ Adherence to antiretroviral medication results in reduced HIV transmission and improved health \\ outcomes, yet challenges with medication adherence remain. A Collaborative Care Program was \\ developed with a community pharmacy integrating a multi-dose adherence packaging service. We \\ surveyed program participants to assess their satisfaction with this program and found an overall positive \\ sentiment toward the program, that the program helped with reducing missed doses, and all patients \\ would recommend the program to others.

\section{Keywords} \\ Human immunodeficiency virus (HIV), blister packaging, medication adherence, viral suppression

\section{Creative Commons License} \\ cc) (i) $\ominus$ \\ This work is licensed under a Creative Commons Attribution-Noncommercial-No Derivative Works 4.0 \\ License.

\section{Cover Page Footnote} \\ Acknowledgements. The authors would like to thank Valentina Orduna and Monica Arroyo for translating \\ the survey into Spanish and administering the survey to Spanish-speaking patients in person when \\ needed.

\section{Authors} \\ Holly Groteluschen, Harlan Sayles, Rebecca Osborn, Joshua P. Havens, Sara Bares, and Jasmine R. \\ Marcelin
}




\title{
Customized Blister Packaging for Patients Living With HIV: Assessment of Patient Attitudes and Satisfaction
}

\author{
Holly Groteluschen 1 , Harlan Sayles ${ }^{2}$, Rebecca Osborn ${ }^{3}$, Joshua P. Havens ${ }^{4,5}$, Sara H. Bares ${ }^{5}$, Jasmine R. Marcelin \\ ${ }^{1}$ University of Nebraska Medical Center, College of Medicine, Omaha, NE \\ ${ }^{2}$ University of Nebraska Medical Center, College of Public Health Department of Biostatistics, Omaha, NE \\ ${ }^{3}$ Yale School of Medicine, Department of Internal Medicine, New Haven, CT \\ ${ }^{4}$ University of Nebraska Medical Center, Department of Pharmacy Practice, Omaha, NE \\ ${ }^{5}$ University of Nebraska Medical Center, Department of Infectious Diseases, Omaha, NE
}

\begin{abstract}
Introduction: Adherence to antiretroviral medication results in reduced HIV

transmission and improved health outcomes, yet challenges with medication adherence remain.
\end{abstract}

Methods: A Collaborative Care Program was developed with a community pharmacy integrating a multi-dose adherence packaging service. We surveyed program participants to assess their satisfaction with this program.

Results: All participants reported that the blister packaging program helped them miss fewer doses of their ART medication. Similarly, all agreed that they would recommend the blister packaging program to others.

Conclusion: We found an overall positive sentiment toward the program, that the program helped with reducing missed doses, and all patients would recommend the program to others.

\section{Introduction}

Since the beginning of the HIV epidemic, more than 70 million people have been infected with the virus, and an estimated 35 million have died. By the end of 2016, approximately 36.7 million people around the world were living with HIV. ${ }^{1}$ Antiretroviral therapy (ART) allows for immune reconstitution in people living with HIV (PLWH) by suppressing HIV replication and increasing CD4+ counts. Increased access to ART has prevented a projected 5.2 million AIDS-related deaths in low- and middle-income countries from $1995-2010 .^{2}$ Adherence to antiretroviral regimens can reduce HIV transmission and increase the patient's life expectancy. ${ }^{3}$ However, an estimated $50 \%$ of PLWH fail to take their medications as prescribed. ${ }^{4}$ Inconsistent ART adherence can lead to treatment failure and drug resistance, increasing the risk for development of AIDS and AIDS-related conditions leading to death. ${ }^{5}$ Reasons for medication non-adherence vary, including inability to afford medications, drug regimen complexity, poor health literacy, forgetfulness, impact of co-existing psychiatric conditions, transportation problems, and social or self-stigmatization. ${ }^{4}$ Some strategies to improve medication adherence include dose simplification, specialized packaging, and directly observed therapy. ${ }^{6}$ There is an association between patient satisfaction with health care services and adherence to ART, and using an integrated specialty pharmacy to provide refill reminders, medication delivery, and adherence calls have led to improved immune markers and viral suppression in patients living with HIV.,

Beginning in 2013, the Nebraska Medicine HIV Clinic partnered with Elmwood Pharmacy (a community pharmacy adjacent to the clinic) to develop a Collaborative Care Program (CCP). As part of the CCP, medications are placed in multi-dose adherence blister packaging which is dispensed every two weeks. The packages include the patient's daily medications including their ART, with as needed medications dispensed in separate bottles. Patients receive two weeks supplies of medication, unless they live outside the Omaha metro area, which necessitates mail delivery of one month's worth of medication. Patients are required to return the previous two packages in order to receive new packages. This returning of their old packages enables the pharmacy to keep records of missed doses and recommend adjustment in timing of medication dosing based on their findings.

The patients are referred to the blister packaging program for a variety of reasons. Some are visually impaired or require closer supervision, many are prescribed multiple medications, and most simply forget to take their medication. Preliminary data from the pilot program has demonstrated an impact on virologic suppression, although patient-related attitudes and satisfaction with the program have not previously been assessed. ${ }^{9}$ This information could be utilized to improve the program and further tailor it to our patients, as it is a valuable adherence tool for PLWH.
Therefore, we aimed to evaluate attitudes and satisfaction with the blister packaging program.

\section{Methods}

People living with HIV receiving care at the UNMC HIV Clinic and receiving medications via blister packaging from the Elmwood Pharmacy were invited to complete a survey. How did you develop the survey? Patients who enrolled in the blister packaging program from 2013 through December 2018 were invited to participate. Paper surveys were mailed out to patients' home address on file and if not completed/returned by the time of an in-person visit, the survey was administered on-site, by telephone, or by the pharmacy courier. The survey was administered in Spanish for those patients that required it.

Data Storage. Study data were collected and managed using the REDCap electronic data capture tools hosted at the University of Nebraska Medical Center. Service and support is provided by the Research Information Technology Office (RITO), which is funded by the Vice Chancellor for Research.

Data Analysis. The descriptive analysis uses frequencies and percentages to describe categorical data and medians and interquartile ranges to describe continuous data. Given the relatively small size of the sample, possible associations of patient demographic and clinical characteristics with medication adherence, barriers to medication adherence, and satisfaction with the use of blister packaging were not evaluated using hypothesis testing methods.

Ethical approval. This project was reviewed and approved as minimal risk by the University of Nebraska Medical Center Institutional Review Board (607-18-EP).

\section{Results}

Forty-four patients met criteria for inclusion. Twenty-three surveys were completed (52.3\% 
response rate); eight returned by mail, 13 administered in-person during a clinic visit, one administered over the phone, and one returned via a courier. Three patients declined participation and 18 patients did not respond. The median number of years living with HIV and on ART were 16.2 and 8.7, respectively. The median age of the participants was 54 , with almost equal distribution of sex assigned at birth. The participants were largely non-Hispanic white (52\%) with $24 \%$ and $19 \%$ of participants identifying as Black and Hispanic, respectively. Eighty-two percent of participants were unemployed, and $60 \%$ reported income below $100 \%$ of the Federal Poverty Level. Most participants had suppressed viral loads (95\%; <50 copies/ $\mathrm{mL}$ ) with a median CD4+ count of 621 cells/ mm. ${ }^{3}$ A large majority of respondents had at least one mental health diagnosis $(81 \%)$ and $38 \%$ reported substance use. Twenty-two respondents $(95 \%)$ were on a multiple-pill regimen taken once daily, and $85 \%$ had no change in their ART medication regimen. A large majority (71\%) were taking an integrase strand transfer inhibitor-based ART regimen. Thirty-eight percent of participants reported having someone at home who helped them remember to take their medication. A summary of patient demographics can be found in Table 1.

The most common reasons for missed doses identified by participants were "forgetting" (58\%), and "not feeling like taking the medicine" (11\%) (Figure 1). All participants reported that the blister packaging program helped them miss fewer doses of their ART medication. Similarly, all agreed that they would recommend the blister packaging program to others. The most helpful aspect of the program reported was being able to see when they had missed a dose (100\% reported this as being "very helpful"). Other helpful aspects included the medicine being delivered to their home ( $90 \%$ reported "very helpful") and better organization (95\% reported "very helpful") (Figure 2).

\section{Discussion}

In this survey study to evaluate the perspectives and satisfaction of patients enrolled in the CCP blister packaging program, nearly all participants reported high satisfaction. Many respondents appreciated being able to see potential missed doses and all respondents indicated satisfaction with the program by stating that they would recommend the program to others. Our findings that missed doses are often due

Table 1.

Participant demographics and clinical characteristics.

\begin{tabular}{|c|c|}
\hline Characteristic & $\begin{array}{l}\text { Median (IQR) } \\
\text { or } n(\%)\end{array}$ \\
\hline Age, years & $54(48,58)$ \\
\hline \multicolumn{2}{|l|}{ Sex assigned at birth } \\
\hline Female & $10(48)$ \\
\hline Male & $11(52)$ \\
\hline \multicolumn{2}{|l|}{ Race/Ethnicity } \\
\hline Non-Hispanic White & $11(52)$ \\
\hline Non-Hispanic Black & $5(24)$ \\
\hline American Indian / Alaska & $1(5)$ \\
\hline Native & $4(19)$ \\
\hline \multicolumn{2}{|l|}{ Hispanic } \\
\hline \multicolumn{2}{|l|}{ Marital Status } \\
\hline Single & $10(48)$ \\
\hline Married & $3(14)$ \\
\hline Significant Other / Life Partner & $3(14)$ \\
\hline Divorced & $5(24)$ \\
\hline \multicolumn{2}{|l|}{ Work Status } \\
\hline Employed for wages & $4(19)$ \\
\hline Out of work (involuntary) & $2(10)$ \\
\hline Out of work (voluntary) & $2(10)$ \\
\hline Unable to work & $13(62)$ \\
\hline \multicolumn{2}{|l|}{ Income } \\
\hline $\begin{array}{l}\text { Below } 100 \% \text { of the federal } \\
\text { poverty level }\end{array}$ & $12(60)$ \\
\hline $\begin{array}{l}\text { At least } 100 \% \text { of the federal } \\
\text { poverty level }\end{array}$ & $8(40)$ \\
\hline HIV Duration, years & $16.2(12.2,21.7)$ \\
\hline
\end{tabular}

\begin{tabular}{ll} 
Characteristic & $\begin{array}{l}\text { Median (IQR) } \\
\text { or } \mathbf{n}(\%)\end{array}$ \\
\hline ART Duration, years & $8.7(4.9,14.4)$ \\
\hline Last Viral Load < 50 copies/mL & $20(95)$ \\
\hline Last CD4 cells/mm ${ }^{3}$ & $621(398,976)$ \\
\hline $\begin{array}{l}\text { Regimen Anchor Type } \\
\text { Integrase Inhibitor }\end{array}$ & $15(71)$ \\
$\begin{array}{l}\text { Non-nucleotide Reverse } \\
\text { Transcriptase Inhibitor }\end{array}$ & $1(5)$ \\
Protease Inhibitor & $5(24)$
\end{tabular}

\begin{tabular}{ll}
\hline ART Pill Count & $6(29)$ \\
1 & $10(48)$ \\
3 & $3(14)$ \\
5 & $2(10)$ \\
\hline Total Number of Medications & $9(7,11)$ \\
\hline Mental Health Diagnosis & $17(81)$ \\
\hline History of Opportunistic Infection & $5(24)$ \\
\hline Diabetes & $7(33)$ \\
\hline Hypertension & $11(52)$ \\
\hline Cardiovascular Disease & $13(62)$ \\
\hline Kidney Disease & $3(14)$ \\
\hline Substance Use & $8(38)$
\end{tabular}

HIV: Human Immunodeficiency Virus ART: Antiretroviral Therapy

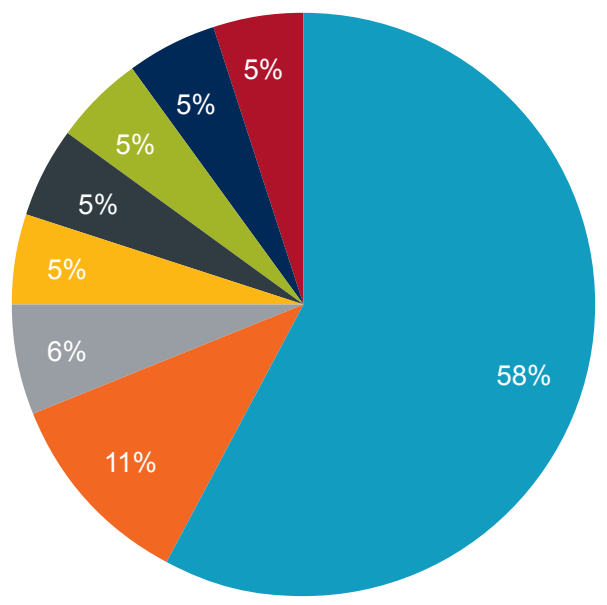

Didn't want other people to know

Did not like being reminded of my HIV

Too many pills

Side effects

Too busy

No way to get to the pharmacy

Just didn't feel like taking the medicine

Forgot

Figure 1. Patient-reported biggest reasons for missed doses of ART $(n=21)$.

to forgetfulness and lack of transportation aligns with other reported common adherence barriers. ${ }^{10}$ Patients who participate in this blister packaging program were enrolled due to prior issues with non-adherence. Almost all of the patients in the program who responded to the survey had controlled viral loads at the time of the survey, indicating that the patients were likely having improved adherence with their ART after enrollment in the program. An early evaluation of this blister packaging program cohort showed that program participants had improved viral suppression after enrollment. ${ }^{9}$ The participant population had a high prevalence of comorbid conditions, predominantly related to mental health diagnoses. Despite many participants being on single-tablet regimens of ART, 

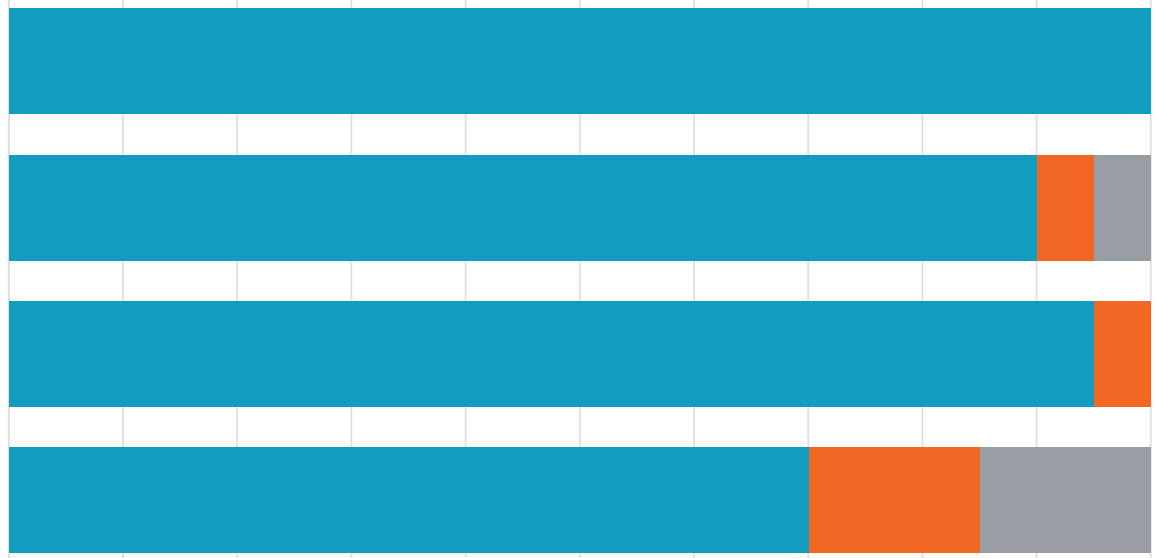

0 10 $20 \quad 30$ 40 50 60 70 80 90 100
Somewhat Helpful

Figure 2. Patient-reported most helpful aspects of blister packaging program $(n=21)$.

their concomitant comorbidities resulted in increased pill burden, which could impact adherence without the blister packaging program.

The patients enrolled in the blister packaging program are a small percentage of the 13001400 patients in the clinic on ART. To study this process on a larger scale, a multi-center study involving other community pharmacies could be useful. Furthermore, a program like this could have applications outside of HIV care, for patients followed by primary care clinicians managing conditions like hypertension, hyperlipidemia, and diabetes. Increased adherence has previously been demonstrated in trials of blister packaging programs for psychiatric medications and hypertensive medications. ${ }^{11,12}$ A study investigating the use of blister packaging for multiple medications in elderly patients showed improvements in blood pressure and LDL measurements. ${ }^{13}$ This broader application could subsequently lead to improved overall outcomes of our patient populations, particularly those at risk for more severe disease. These previous studies looked only at efficacy of the programs, and further studies on patient satisfaction may be helpful.

Strengths of this study include the relatively high response rate for a survey study, with
$52 \%$ of the surveys sent out being completed. The generalizability of the study is limited by the small sample size. Another limitation of note is a response bias, in that the demographic and viral suppression data were only collected in patients who responded to the survey. More motivated patients were more likely to participate in the survey, therefore these results (both satisfaction and corresponding markers of HIV control) may not be as applicable in patients who did not complete the survey.

Overall, the results show a high level of participant satisfaction with the blister packaging program. Improvements in medication adherence through the use of a collaborative pharmacy-based adherence packaging program may increase PLWHs ability to achieve and maintain virologic suppression.

Funding. The authors report no financial support for this work.

Potential conflicts of interest. S.H.B. and J.P.H. report grant funding to their institution from Gilead Sciences, Inc. All authors have submitted the ICMJE Form for Disclosure of Potential Conflicts of Interest.

https://doi.org/10.32873/unmc.dc.gmerj.2.2.002

\section{References}

1 World Health Organization (WHO). Summary of the Global HIV epidemic (2018). 2018; http://www.who. int/gho/hiv/en/. Accessed 8.2.20.

2 Fettig J, Swaminathan M, Murrill CS, et al. Global Epidemiology of HIV. Infectious disease clinics of North America. 2014;28(3):323-337.

3 Cohen MS, et al. Antiretroviral therapy for the prevention of HIV-1 transmission. New England Journal of Medicine. 2016;375(9):830-839.

4 Brown MT, and Bussell JK. Medication Adherence: WHO Cares? Mayo Clinic Proceedings. 2011;86(4):304-314.

5 Quinn TC. HIV epidemiology and the effects of antiviral therapy on long-term consequences. AIDS (London, England). 2008;22(Suppl 3):S7-12.

6 Kripalani S, Yao X, and Haynes R. Interventions to enhance medication adherence in chronic medical conditions: A systematic review. Archives of Internal Medicine. 2007;167(6):540-549.

7 Leon C, Koosed T, Philibert B, et al. HIV/AIDS health services in Manaus, Brazil: patient perception of quality and its influence on adherence to antiretroviral treatment. BMC health services research. May 30 2019;19(1):344.

8 Barnes E, Zhao J, Giumenta A, et al. The Effect of an Integrated Health System Specialty Pharmacy on HIV Antiretroviral Therapy Adherence, Viral Suppression, and CD4 Count in an Outpatient Infectious Disease Clinic. Journal of managed care \& specialty pharmacy. Feb 2020;26(2):95-102.

9 Osborn R, Havens J, Swindells S, et al. Adherence Packaging as Part of a Collaborative Care Program to Improve HIV Viralogic Suppression. Paper presented at: ACTHIV Conference: A State-of-the Science Conference for Frontline Health Professionals 2018; Chicago, IL.

10 Legesse TA, and Reta MA. Adherence to Antiretrovira Therapy and Associated Factors among People Living with HIV/AIDS in Hara Town and Its Surroundings, North-Eastern Ethiopia: A Cross-Sectional Study. Ethiopian journal of health sciences. May 2019;29(3):299-308.

11 Tan BY, Shafie AA, Hassali MAA, et al. Assessment of medication adherence and the costs associated with a calendar blister pack intervention among hypertensive patients in Malaysia: A randomized controlled trial. SAGE Open Med 2017;5:2050312117709189-2050312117709189.

12 Gutierrez PM, Wortzel HS, Forster JE, et al. Blister Packaging Medication Increases Treatment Adherence in Psychiatric Patients. J Psychiatr Pract. Sep 2017;23(5):320-327.

13 Lee JK, Grace KA, and Taylor AJ. Effect of a Pharmacy Care Program on Medication Adherence and Persistence, Blood Pressure, and Low-Density Lipoprotein CholesterolA Randomized Controlled Trial. JAMA. 2006;296(21):2563-2571. 